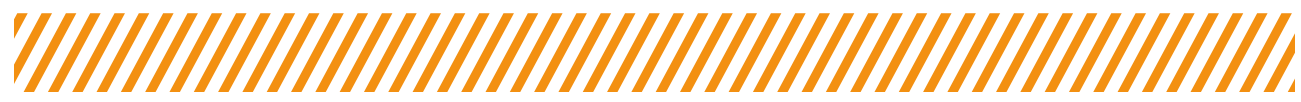

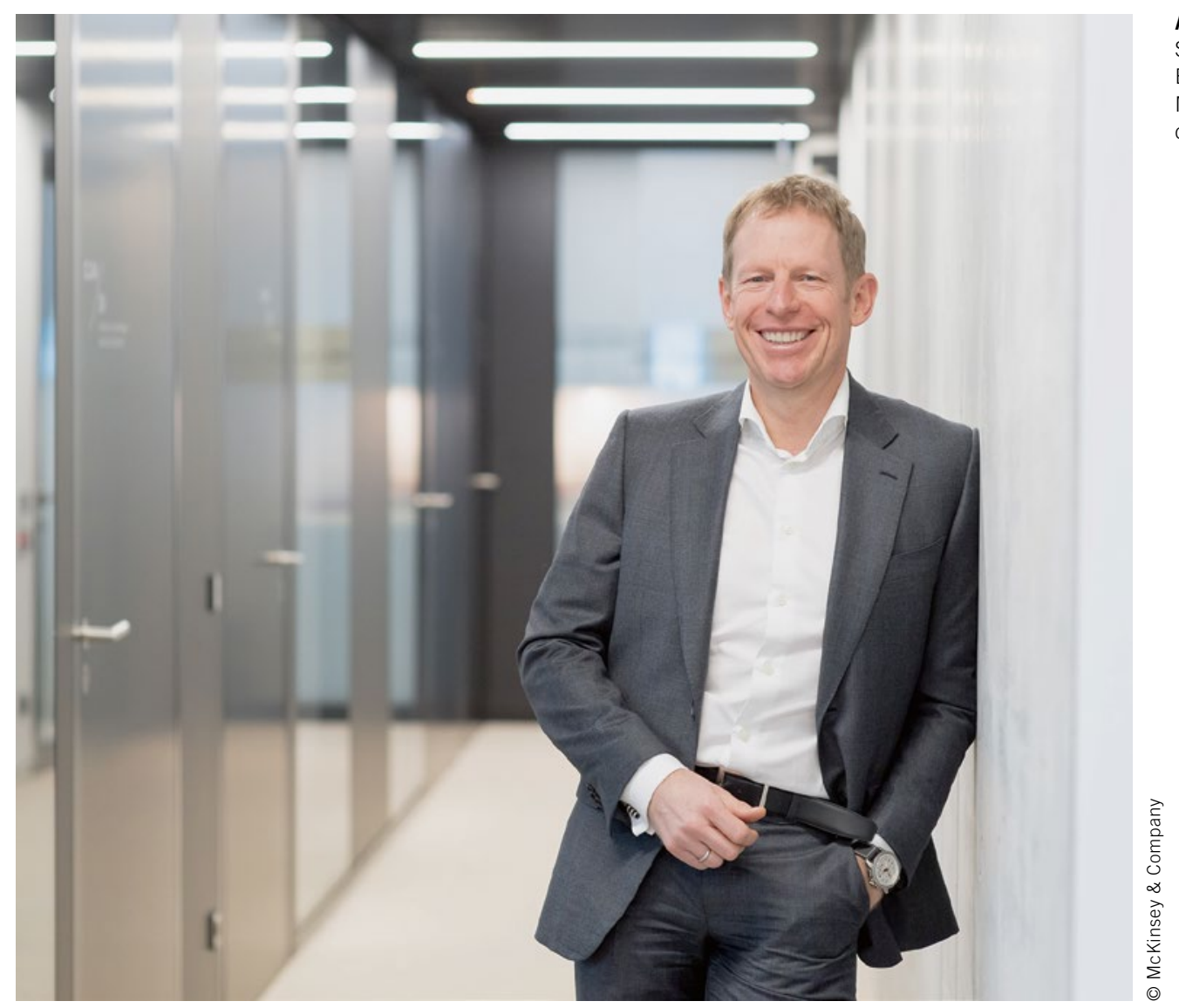

Andreas Tschiesner

Seniorpartner im Münchner Büro der Unternehmensberatung McKinsey \& Company und leitet die europäische Automobilberatung

\section{Corona, und dann?}

Die Corona-Krise fordert die Automobilindustrie heraus: Neben einer entschlossenen Reaktion auf die akute Krise, dem Schutz von Leben und Gesundheit und der Sicherung der wirtschaftlichen Basis sind auch Langfriststrategien gefragt. Fünf Schritte helfen dabei. Praktisch alle Unternehmen der Automobilindustrie haben den ersten Schritt der Krisenbewältigung, Entschlossenheit (Resolve), erfolgreich absolviert. Frühere Rezessionen liefern wertvolle Erkenntnisse darüber, wie Unternehmen ihre Krisenfestigkeit (Resilience) verbessern können. Jene, die vor Beginn eines Abschwungs saubere Bilanzen haben, trotz Krisenzeiten grundlegende Entscheidungen treffen und ein organisches Umsatzwachstum aufrechterhalten, bewältigen die Krise deutlich besser. Produktionseinrichtungen wieder hochzufahren (Return), ist manchmal schwieriger, als sie stillzulegen. Es erfordert einen strukturierten Ansatz, um die Lieferkette wiederzubeleben. Angesichts der Komplexität der weltweiten Lieferketten ist das koordinierte Hochfahren der Fabriken erfolgsentscheidend. Die Coronavirus-Pandemie könnte die Art und Weise, wie wir leben, arbeiten und Technologie einsetzen, grund- legend verändern (Reimagine). Viele Organisationen versuchen, strukturelle Veränderungen anzugehen oder zu beschleunigen, sei es im Go-to-Market-Ansatz, bei Kooperationen und Allianzen, durch neue Formen der Arbeitsorganisation, eine veränderte geografische Aufstellung oder einer Verlagerung von Kosten.

Die Auswirkungen der Covid-19-Krise werden auch das Mobilitätsverhalten langfristig beeinflussen. Die Entwicklung der „New-normal“-Perspektive zu Mobilität ist eine der wichtigsten Herausforderungen in einer erfolgreichen Langfriststrategie. Dies betrifft den künftigen Mobilitätsmix in Städten ebenso wie neue Geschäftsmodelle sowie horizontale Industriekooperationen. Die Anpassung der Kostenstrukturen an das „New Normal“ ist eine weitere, essenzielle Aufgabenstellung. Seit mehr als 100 Jahren ist die Automobilindustrie eine treibende Kraft für wirtschaftlichen und gesellschaftlichen Fortschritt. Der fünfstufige Ansatz kann Automobil- und Industrieunternehmen helfen, diese Pandemie zu überstehen und sich danach schnell wieder zu erholen. 